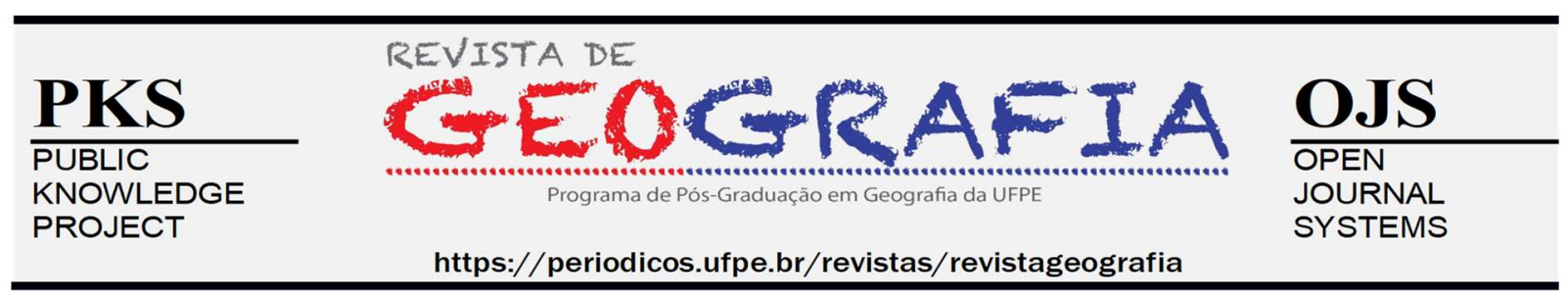

\title{
A ALFABETIZAÇÃO CARTOGRÁFICA NA SUA RELAÇÃO COM O LETRAMENTO E A CULTURA DIGITAL
}

\author{
Daniel Cardoso Alves ${ }^{1}$ \\ ${ }^{1}$ Universidade do Estado de Minas Gerais (UEMG), E-mail: dca.uemg@gmail.com, http://orcid.org/0000-0002- \\ 1597-5180
}

Artigo recebido em 12/01/2020 e aceito em 28/04/2020

\begin{abstract}
RESUMO
Sob o entendimento de letramento como prática social situada e de que o ensino da Geografia perpassa, prioritariamente, por uma concepção plural e ampliada do termo linguagem, que o conecta aos novos campos de estudo e às novas perspectivas sobre letramento e seus componentes, este artigo objetiva problematizar a concepção de alfabetização cartográfica na sua relação com a cultura digital como forma de se repensar as reconfigurações pelas quais passa o processo de ensino e de aprendizagem da Cartografia e dos seus recursos elementares, em especial o mapa temático. Para compreendermos um tipo específico de leitura, a cartográfica, nos ancoramos em teóricos que possibilitaram a aproximação das discussões sobre linguagem cartográfica assumida pelos estudos sobre letramento o papel da multimodalidade na abordagem dos multiletramentos. A pesquisa, nesse sentido, se caracteriza como uma revisão de literatura. Concluímos defendendo que a Gramática do Design Visual (GDV) tem muito a contribuir para a compreensão do processo de letramento a partir dos recursos próprios da ciência geográfica, como no caso dos mapas temáticos, que se constituem, na concepção de Moreira (2007), como o repertório mais conspícuo de representação e leitura do mundo.
\end{abstract}

Palavras-chave: Alfabetização; Cartografia; Cultura digital; Gramática do Design Visual (GDV); Letramento.

\section{CARTOGRAPHIC LITERACY IN ITS RELATIONSHIP TO LETTERING AND DIGITAL CULTURE}

\begin{abstract}
Under the understanding of literacy as a situated social practice and that the teaching of Geography permeates, primarily, a plural and expanded conception of the term language, which connects it to the new fields of study and to the new perspectives on literacy and its components, this article aims to problematize the conception of cartographic literacy in its relation to digital culture as a way of rethinking the reconfigurations through which the process of teaching and learning of Cartography goes through and of its elementary resources, in particular the thematic map. To understand a specific type of reading, cartographic, we are anchored in theorists that allowed the approximation of discussions on cartographic language assumed by studies on literacy the role of multimodality in the approach of multiliteracies. The research, in this sense, is characterized as a literature review. We conclude by arguing that the Grammar of Visual Design (GDV) has much to contribute to the understanding of the literacy process from the own resources of geographic science, as in the case of thematic maps, which constitute, in Moreira's conception (2007), as the most conspicuous repertoire of representation and reading in the world.
\end{abstract}

Keywords: Literacy; Cartography; Digital culture; Visual Design Grammar (GDV). 


\section{INTRODUÇÃO}

É por meio da linguagem que o sujeito comunica e se faz comunicar, ou seja, tanto se expressa, como cria e apreende os significados e sentidos impressos nas diversas formas de representação da língua. A linguagem é, nesse sentido, uma faculdade humana de significação dos sistemas comunicativos (signos) nela representados, que se constitui conceitualmente, segundo Bagno et. al. (2014), de dois aspectos fundamentais: a verbalização e a não verbalização. Enquanto verbal, ela é concebida como um conjunto de signos linguísticos que dão sentido às formas orais, escritas ou gestuais da língua; enquanto não verbal, ela é um termo que abrange signos diversificados (cores, sons, formas, tamanhos, ícones, entre outros) que são, também, carregados de significados e sentidos.

A associação desses dois aspectos influenciou a literatura contemporânea, trazendo à baila novas concepções sobre os estudos da linguagem, o que representou um salto nas abordagens tradicionais estáveis e lineares que até então predominavam acerca do conceito de letramento e seus componentes. Esse salto foi possibilitado por linguistas modernos que, influenciados por uma perspectiva interacionista sócio-discursiva da língua, contribuíram para a redefinição e mudança no paradigma dos usos e significados das atividades de leitura e escrita e, consequentemente, para a inserção dos novos estudos sobre letramento, o qual passou a ser compreendido, conforme Street (2012), como uma prática social situada, ou seja, relacionado à dinâmica contextual, à ideia do poder e da ideologia, à identidade, às interações intersubjetivas e ao agenciamento dos grupos e, portanto, não mais como um treinamento generalista de habilidades técnicas ou, nas palavras de Soares et. al. (2014), não mais como uma alfabetização no sentido restrito do domínio do sistema alfabético-ortográfico e da mecânica aprendizagem do ler e do escrever.

Assim compreendida no duplo aspecto verbal e não verbal, a linguagem tornou-se objeto de análise de campos de estudos, como a semiótica (ou semiologia) ${ }^{1}$, que ampliaram o conceito de letramento e, por conseguinte, das práticas de leitura e escrita, para além dos aspectos orais, escritos ou gestuais da língua, abrangendo novos signos como tamanho, forma, cor, som, ícones variados, movimento e posicionamento. Esses recursos semióticos, combinados em diversos modos, passaram a ser compreendidos como produtores das diferentes possibilidades, potencialidades e restrições que conferem significados e sentidos ao que se lê e escreve.

\footnotetext{
${ }^{1}$ A Associação Internacional de Estudos Semióticos, em 1969, decidiu pelo uso exclusivo do termo Semiótica, sem, contudo, invalidar os estudos anteriores sob a denominação de Semiologia (NÖTH, 1995).
} 
Esse processo híbrido-linguístico de produção e significação da leitura e da escrita é entendido por Dionísio e Vasconcelos (2013, p. 34-36) como "multimodalidade", em que a combinação dos variados modos mobiliza diferentes recursos semióticos, potencializa a capacidade humana “visuoverbal (visual-pictorial e verbal-auditiva)" e produz melhores efeitos na apreensão dos significados e sentidos por meio das atividades de leitura e escrita. Semelhantemente, Kress (2003) vincula o letramento ao campo da multimodalidade, considerando que o escrever é uma impressão de sentido simbólico e social ao que será lido. Conforme tradução das palavras do autor: "A criação do texto é um ato semiótico em que o significado é relevante em todos os aspectos, porque é também um ato social com consequências sociais" (KRESS, 2003, p.69).

Dessa forma, Kress (2003) concebe leitura e escrita como práticas multimodais, as quais, conforme Frade et. al. (2014), são potencializadas em ambiente digital, dada a maior articulação entre sistemas ideográficos e alfabéticos propiciada pela combinação variada entre signos sonoros, verbais e visuais. Em suma, a diversidade cultural, linguística e tecnológica, tanto contribuiu para abranger a concepção de linguagem como gênero discursivo que mobiliza variados recursos semióticos e demanda múltiplos conhecimentos, habilidades e procedimentos, quanto resultou em uma perspectiva de letramento como prática social situada, uma vez que, segundo Street (2012), é sensível aos contextos sociais de variação que, para Kress (2003), assume formas multimodais de comunicação, vinculando-se ao campo dos estudos sobre multiletramentos, o que contribuiu para reconfigurar as práticas de leitura e escrita, reestruturar o conhecimento e trazer à tona outros recursos textuais possíveis para o processo de significação comunicativa.

Essa concepção abrangente da linguagem ampliou a capacidade humana de aprendizagem dos gêneros textuais dela derivados, que esteve por muito tempo centrada no aspecto verbal. Com a inserção da linguagem e do letramento no campo dos estudos sobre multiletramentos, Dionísio e Vasconcelos (2013) entendem que os gêneros textuais foram redefinidos enquanto categoria psicossocial, de caráter histórico e reconhecimento social, pelo que, o verbal passa a ser apenas um dos vários modos de representação multimodal, inclusive, em muitos textos, a escrita por exemplo, segundo Kress e Bezemer (2009), deixa de ser o elemento central para a compreensão dos significados e sentidos do processo de comunicação.

Para Kress e Bezemer (2009), o texto sob o prisma da multimodalidade passa a ser concebido como uma entidade semiótica coesiva, coerente e de complexo significado, cuja 
mensagem comunicativa que ele expressa é resultante da complexa situação social que o gerou. Admitindo essa acepção, a combinação variada dos modos presentes nos textos e as dimensões sociais, políticas, históricas, econômicas, culturais, ambientais e tecnológicas devem ser consideradas pelas práticas de leitura e escrita atentas a uma perspectiva multimodal, em que a interação entre linguagem verbal e não verbal é a característica principal da multimodalidade que (re)significa e amplia as possibilidades comunicativas do texto.

Ao considerarmos que texto é "qualquer instância comunicativa em qualquer modo semiótico ou em qualquer combinação de modos" (KRESS, 2003, p. 48), entendemos que recursos essencialmente semióticos, a exemplo do mapa temático que, para Moreira (2007, p. 67-68) refere-se ao "símbolo e à forma de linguagem reconhecida da Geografia [...], (sendo o) repertório mais conspícuo do vocabulário geográfico. E trata-se da melhor representação do olhar geográfico", cuja forma de linguagem não verbal apresenta-se como preponderante para o cumprimento da sua função social de "[...] comunicar o conhecimento de poucos para muitos, por conseguinte ele deve ser elaborado de forma a realmente comunicar" (LOCH, 2006, p. 27), constitui-se como um gênero multimodal por natureza que, para o seu mister, utiliza-se da imagem como o principal modo de comunicação ${ }^{2}$ composto por signos pensados e elaborados com a finalidade de possibilitar a compreensão correlacionada, pelos leitores diversos, das diferenças e semelhanças nele, simbólico e imageticamente, representadas.

O mapa temático, por suas inerentes características, constitui-se como um dos principais elementos de representação dos fenômenos geográficos utilizados pela Cartografia, aqui entendida à luz de Bertin (1980) como linguagem de representação visual, não verbal, não linear e com regras gramaticais próprias, ou seja, um tipo de linguagem que, parafraseando Rojo (2013), se caracteriza como híbrida, multimodal, em que "múltiplos gêneros linguísticos como mapa, texto, imagem e som se entrecruzam".

Todavia, valer-se do mapa temático com vistas a uma comunicação efetiva do perceptível e do imperceptível geográfico, no qual recursos semióticos mesclam-se produzindo significados e sentidos requer, com base em Kress (2003), uma concepção de linguagem que seja multimodal e de outras formas de letramentos, segundo Street (2012), no plural e indissociáveis dos múltiplos contextos socioculturais, linguísticos e tecnológicos como requisitos para ultrapassar a restrita noção de alfabetização cartográfica e a popularização

\footnotetext{
${ }^{2}$ Segundo Jewitt e Kress (2003), não existe comunicação monomodal.
} 
conceitual equivocada e generalizada que, historicamente, foi conferida a esse instrumento elementar da Cartografia.

A alfabetização cartográfica no seu sentido restrito que incide na conceituação equivocada e generalizada acerca do mapa temático apresenta-se como o motivo instigador deste artigo, tendo em vista que, é comum as pessoas não relacionarem os significantes cartográficos com os seus significados, bem como, nominarem de mapa tudo aquilo que elas querem representar, ainda que não seja necessariamente um mapa na sua concepção originária. Assim, toda e qualquer forma de representação (gráficos, listas, quadros, tabelas, entre outras) passa a ser chamada de mapa. Dessa forma, entendemos alfabetização cartográfica e/ou geográfica, conforme Castellar (2010), a partir de uma concepção ampliada, ou seja, enquanto letramento cartográfico e/ou geográfico que se define como "o ponto de partida para estimular o raciocínio espacial do aluno, articulando a realidade com os objetos e os fenômenos que querem representar, na medida em que se estrutura a partir das noções cartográficas" (CASTELLAR, 2010, p. 24).

Entretanto, ainda que para um leitor comum o que importa seja a finalidade imediata do recurso (a função comunicativa do que vulgarmente ele chama de mapa), para os profissionais da ciência que produz esse recurso, não há espaço para o desconhecimento dos conceitos, dos procedimentos de elaboração e das interpretações inerentes aos recursos de representação adotados pela Cartografia, em especial, o mapa temático. Ou seja, não deve ser comum falarmos de geógrafos "iletrados visuais", expressão utilizada por Kress e Van Leuween (2006) para caracterizar sujeitos que não dominam a capacidade de leituras outras que sejam constituídas exclusivamente de recursos verbais.

Em defesa desse argumento, ao tentarmos investigar o perfil cartográfico dos estudantes de Geografia das instituições de ensino superior (IES) no Brasil, algumas questões ${ }^{3}$ revelam-se fundantes: Com que inovações, em quais condições e como se configuram as práticas de leitura cartográfica adotadas nesse curso? Que alfabetização (para qual tempo e espaço?) proclamam os currículos de bacharelado e licenciatura desse curso? Quais práticas envolvendo a cultura digital são vivenciadas/praticadas pelos discentes desse curso e como eles lidam com elas?

\footnotetext{
${ }^{3}$ Essas questões não serão aprofundadas neste artigo. Elas serviram de motivação que levaram ao objetivo geral do estudo: problematizar a concepção de alfabetização cartográfica na sua relação com a cultura digital como forma de se repensar as reconfigurações pelas quais passa o processo de ensino e de aprendizagem da Cartografia e dos seus recursos elementares, em especial o mapa temático.
} 
Quem são esses discentes no tempo contemporâneo? Eles estão incluídos ou excluídos da cultura digital?

Essas inquietações nos levaram à necessidade de se realizar, incialmente, um “estado do conhecimento ${ }^{4 "}$ sobre as perspectivas dos estudos geográficos envolvendo o mapa temático enquanto gênero textual, visual e multimodal. Para tanto, foi realizado no mês de abril do ano de 2019 um levantamento de teses e dissertações, compreendendo o período de 2008 a 2018, predominantemente na base de catálogos disponível no portal da Coordenação de Aperfeiçoamento de Pessoal de Nível Superior (CAPES).

A partir da utilização das palavras-chave "Linguagem", "Semiótica", "Semiologia" e "Multimodalidade", tomadas como descritores, foi possível levantar 40.866 (quarenta mil, oitocentos e sessenta e seis) pesquisas nas 16 (dezesseis) grandes áreas de conhecimento retornadas pela Plataforma Sucupira da CAPES. Essas pesquisas são produções científicas de discentes dos cursos de níveis de mestrado e doutorado, no Brasil, as quais, especificamente com relação à área de conhecimento da Geografia, quantificam-se em apenas 241 (duzentas e quarenta e uma) defesas durante um período de dez anos, ou seja, apenas 0,5\% (meio por cento) das dissertações e teses, no Brasil, com base nos citados descritores, equivalem à referida área.

Esse procedimento investigativo permitiu constatar, conforme demonstra-se no gráfico 1 abaixo, dentre outros achados, que os estudos no campo da "Linguagem", em relação à área de conhecimento da Geografia e às linguagens específicas deste estudo, são amplos (208 pesquisas). Contudo, no que concerne às linguagens semiológica (16 pesquisas) ou semiótica (15 pesquisas) e multimodal (02 pesquisas), focos do estudo aqui proposto, as pesquisas encontradas, em termos quantitativos, são poucas, uma vez que, juntas não ultrapassam a quantidade de 33 (trinta e três) num recorte temporal de dez anos. Constata-se, também, que não há concentração e/ou evolução quantitativa expressiva em nenhum dos anos investigados, considerando que: no ano de 2008 foi registrado o menor número, apenas 12 (doze) pesquisas; de 2009 a 2013 a quantidade variou entre 16 (dezesseis) e 20 (vinte) pesquisas; e, de 2014 a 2018, houve um leve aumento nos dados variando entre 25 (vinte e cinco) e 35 (trinta e cinco) pesquisas, com exceção do ano de 2015 que registrou apenas 17 (dezessete) pesquisas.

\footnotetext{
${ }^{4}$ As pesquisas denominadas "estado da arte" ou "estado do conhecimento" têm caráter bibliográfico. Contudo, o "estado da arte" é mais amplo e não se detém apenas aos estudos dos resumos de dissertações e teses, ao passo que o "estado do conhecimento" privilegia apenas um setor das publicações (ROMANOWSKI; ENS, 2006).
} 


\section{Gráfico 1. Estado do conhecimento de teses e dissertações na área da geografia}

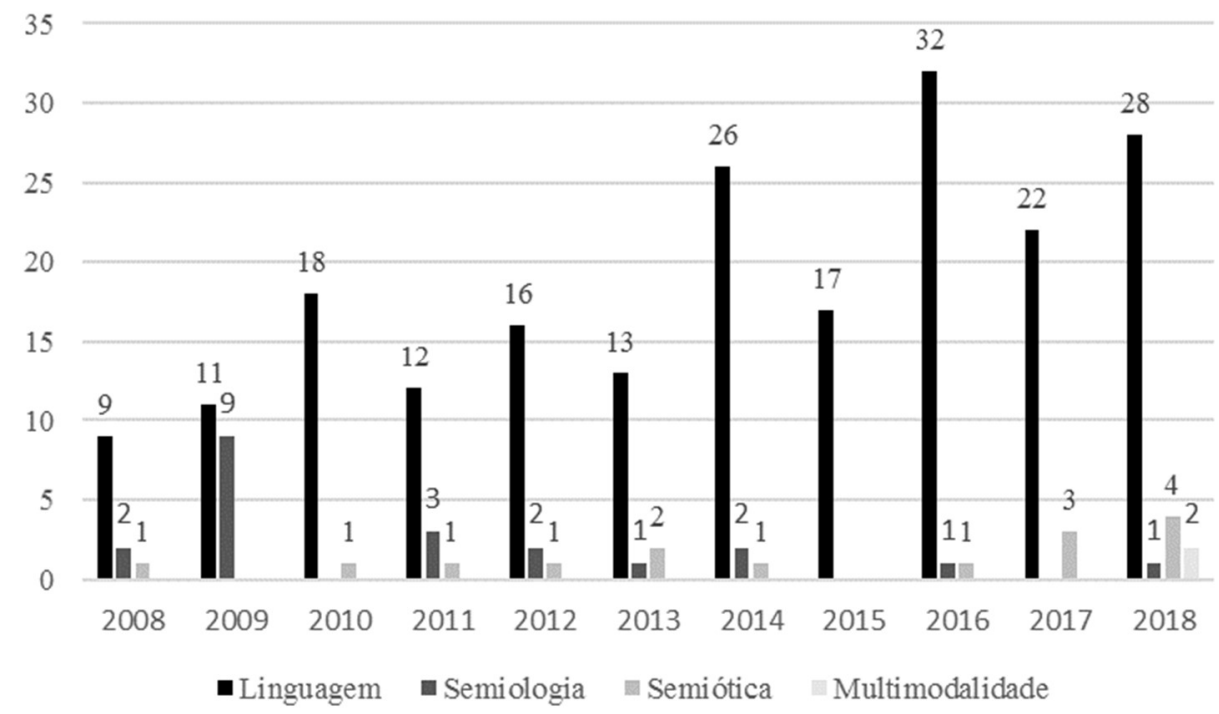

Fonte: Pesquisa do autor na base de catálogo de teses e dissertações da CAPES.

Especificamente sobre a concepção do mapa temático como um gênero multimodal por meio do qual os fenômenos geográficos são representados, as pesquisas registradas na Plataforma Sucupira da CAPES, que se vinculam ao descritor "Multimodalidade", referem-se exclusivamente ao ano de 2018, quantificam-se em uma década minimamente em dois estudos, e têm seus focos, respectivamente, na cartografia escolar do ensino fundamental e no transporte multimodal de mercadorias.

Quanto aos achados em relação aos descritores "Semiologia" e "Semiótica", verificouse, dentre os 31 (trinta e um) registros, apenas um estudo que abordava sobre práticas de leitura cartográfica no ensino superior, vinculado ao descritor "Semiologia", porém, com fundamentação teórica diversa da temática que aqui se apresenta, bem como, sem foco na dimensão digital, o que ratifica a necessidade de mais estudos sobre a alfabetização cartográfica na sua relação com a cultura digital.

Outro fator que instiga o interesse pela temática apresentada neste artigo, diz respeito à compreensão das concepções evidenciadas nos novos estudos sobre letramento comparadas às noções implícitas e explícitas previstas em documentos oficiais como as Diretrizes Curriculares Nacionais (DCN) e os Projetos Pedagógicos dos Cursos (PPC) que orientam a formação dos professores e disciplinam os cursos de graduação nas instituições de ensino superior (IES). Segundo as disposições dos pareceres $n^{\circ}$ 02/2015 e $n^{\circ} 492 / 2001$, exarados pelo Conselho 
Nacional de Educação (CNE), a formação do professor de Geografia precisa estar conexa às novas dinâmicas que interferem nos processos didático-formativos que delinearão o seu perfil enquanto educador, pelo que, conforme Frade et. al. (2014), permanecer alheio à realidade tecnológica que já se vive, não permitirá o aproveitamento das vantagens de aprendizagem possibilitadas por um tipo de alfabetização alterada e potencializada pelo ambiente digital. Assim, a inserção e o ensinamento de práticas de letramento digital no processo de alfabetização, além de ser uma função da escola, envolve a formação do professor.

A partir do entendimento de que ler mapas significa dominar o sistema sócio-semiótico que constitui a linguagem cartográfica, a hipótese que sustenta este estudo baseia-se em Almeida e Passini (1999), segundo as quais: dar significado aos significantes que formam esse instrumento cartográfico, perpassa pela indissociável formação do professor enquanto codificador e decodificador sociocultural desse sistema semiótico, sobretudo, quando se volta o olhar para a sociedade atual marcada pela cultura digital ${ }^{5}$, em que a introdução das Tecnologias Digitais da Informação e Comunicação (TDICs) ${ }^{6}$ ao ensino da Cartografia, conforme Frade et. al. (2014), potencializa o processo de aprendizagem dos recursos multimodais, surgindo perfis de leitor "imersivo" (SANTAELLA, 2004) e "participativo" (JENKINS, 2009), bem como, desestabilizando o conjunto de regras estáticas que distanciavam codificador (autor) e decodificador (leitor) e ensejando a transição do processo restrito de alfabetização cartográfica para uma perspectiva ampliada de "alfabetização digital"7.

Desse modo, defendemos que tornar-se um leitor consciente de mapas presume-se ser também um codificador, pelo que, acreditamos que o processo formativo de leitores cartográficos conscientes, num contexto de cultura digital, sustenta-se em práticas que relacionam leituras cartográficas digitais e analógicas (impressas), como forma de romper a lógica de que "a despeito dos estudantes [...] as geotecnologias ainda estão distantes da sala de aula - embora sejam inúmeras as perspectivas que se vislumbram com o emprego desse ferramental" (OLIVEIRA; NASCIMENTO, 2017, p. 159).

\footnotetext{
${ }^{5}$ [...] Se pensarmos como cultura e não só como suporte, acredito que captamos a essência desta transformação, que é a cultura das redes, do compartilhamento, da criação coletiva, da convergência. São processos vivos de articulação, processos políticos, sociais, que impactam nosso modo de vida, de construção e de formulação. E que encontra no digital não um suporte, mas um modo de elaboração. (MANEVY, 2009, p. 36).

6 "A convergência das tecnologias de informação e comunicação para a configuração de uma nova tecnologia, a digital [...]. Por meio das tecnologias digitais é possível representar e processar qualquer tipo de informação [...]" (KENSKI, 2012, p. 33).

7 "O termo alfabetização digital tem sido usado para designar um tipo de aprendizado da escrita que envolve signos, gestos e comportamentos necessários para ler e escrever no computador e em outros dispositivos digitais" (FRADE, 2014).
} 
Por todo o exposto, o objetivo geral deste artigo reside em problematizar a concepção de alfabetização cartográfica na sua relação com a cultura digital como forma de se repensar as reconfigurações pelas quais passa o processo de ensino e de aprendizagem da Cartografia e dos seus recursos elementares, em especial o mapa temático, um recurso cartográfico responsável pela simbólica "construção social do mundo" (CAPDEVILA; HARLEY, 2002), pertencente ao cotidiano de todos que integram uma sociedade "extremamente semiotizada" (DIONISIO; VASCONCELOS, 2013, p. 34) marcada pelo contexto da "cultura digital” (MANEVY, 2009).

\section{A RELAÇÃo EXISTENTE ENTRE ALFABETIZAÇÃo CARTOGRÁFiCA, LETRAMENTO E TDICS}

A busca por respostas às questões fundantes deste estudo nos insere no campo interno da alfabetização, onde muitas são as tensões: radicalismos teóricos, disputas de currículos, de metodologias, além do uso dos seus dados para culpabilizar professores e sistemas de ensino.

No entanto, quando passamos a entender que alfabetização dialoga com vários objetos sociais e de conhecimento, percebemos que há muitos acordos nesse campo que mais nos unem do que acirram essas tensões, sobretudo, quando pensamos na dimensão cultural do seu uso. Prova disso é que o direito de definir modos de ensinar e a garantia da sua pluralidade estão previstos na Constituição Federal do Brasil:

Art. 206. O ensino será ministrado com base nos seguintes princípios: [...] II liberdade de aprender, ensinar, pesquisar e divulgar o pensamento, a arte e o saber; III - pluralismo de idéias e de concepções pedagógicas, e coexistência de instituições públicas e privadas de ensino [...] (BRASIL, 1988).

Também nos une a ideia de que é preciso um olhar atento para os aprendizes, pois ensinamos a ler e escrever sujeitos com pertencimento sócio, histórico e cultural, que se apropriam da cultura escrita conforme oportunidades negadas ou oferecidas e fazem isso de uma forma ativa. Nas palavras de Freire (2007, p. 41), tornar-se alfabetizado é uma:

Experiência profunda de assumir-se. Assumir-se como ser social e histórico, como ser pensante, comunicante, transformador, criador, realizador de sonhos, capaz de ter raiva porque capaz de amar. Assumir-se como sujeito porque capaz de reconhecer-se como objeto.

Entendemos, assim, que a definição de alfabetização se vincula à sua complexidade sociocultural e à sua dimensão política, sendo impactada por tempos, espaços e finalidades sociais diversos. Por isso, não nos iludamos apenas com a sua dimensão pedagógica. Temos que estabelecer uma relação da alfabetização com conquistas, disputas e acordos que a 
extrapolam, visto que, como nos ensinou Freire (1996), alfabetizar é um ato político porque também é democrático e ético, cujo princípio essencial reside na sua inseparabilidade com a conscientização

Princípio que, de nenhum modo, necessita limitar-se à alfabetização, pois tem vigência para todo e qualquer tipo de aprendizado [...]. O aprendizado das técnicas de ler e escrever ou o das técnicas de manejar o arado ou usar fertilizantes (bem como o aprendizado das idéias de um programa de ação), — enfim, todo aprendizado deve encontrar-se intimamente associado à tomada de consciência da situação real vivida pelo educando (FREIRE, 1967, p. 5).

E como nos ensina Soares (2010, p. 38): alfabetizar, além de desvelar desigualdades sociais dada "a diversidade de suas relações com a sociedade e a cultura", não se restringe à aprendizagem da leitura e da escrita, trata-se de uma apropriação em que "aprender a ler e escrever significa adquirir uma tecnologia, a codificar em língua escrita e de decodificar a língua escrita; apropriar-se da escrita é tornar a escrita própria, ou seja, é assumir com sua propriedade" (SOARES, 1990, p. 39).

A partir dessa acepção, os grandes gargalos que envolvem os debates em torno do campo da alfabetização perpassam pela busca por um tipo de alfabetização que não se refere "a uma habilidade, (mas sim a) um conjunto de habilidades, o que o caracteriza como um fenômeno de natureza complexa, multifacetado" (SOARES, 2010, p. 18), que abrange tanto o domínio das convenções da escrita, como também o impacto social que dele advém. Segundo Soares (2010, p. 82), "sob essa perspectiva funcional da alfabetização, que tem por objeto a função social da escrita, tem-se preferido usar o termo letramento".

A perspectiva social da alfabetização demanda por práticas de aprendizagens situadas, visto que a unicidade metodológica não é suficiente para atender à multiplicidade de tempos e espaços, que requerem cada vez mais tipos específicos de alfabetização (midiática, visual, numérica, cartográfica, digital, etc). Por esse aspecto, passamos a compreender porque esperase tanto da alfabetização nas agendas políticas educacionais. Ela é condição para as outras aprendizagens, encontra-se alterada pelo mundo digital e pode até ser melhorada com as tecnologias. Na Conferência Mundial da Organização das Nações Unidas para a Educação, a Ciência e a Cultura (UNESCO) sobre a Ciência para o século XXI, declarou-se:

Para que um país esteja em condições de atender às necessidades fundamentais de sua população, o ensino das ciências e da tecnologia é um imperativo estratégico. Como parte dessa educação científica e tecnológica, os estudantes deveriam aprender a resolver problemas concretos e a atender às necessidades da sociedade, utilizando suas competências e conhecimentos científicos e tecnológicos (UNESCO, 2003, p. 47). 
Contudo, o que não podemos perder de vista é que quem continua nomeando é a palavra alfabetização. Ou seja, pensar os variados sistemas que envolvem a alfabetização é antes uma questão histórica e cultural e não simplesmente uma questão de mero modismo espaçotemporal.

É certo que, na atualidade, o sistema fonográfico da escrita continua dominante no processo de alfabetização, porém, também é certo que vivemos um tempo marcado pela predominância da cultura digital em que, apesar de haver uma certa permanência do sistema alfabético da escrita, percebemos uma maleabilidade de outros sistemas semióticos que nos instiga a pensar a alfabetização num sentido amplo também no que concerne aos sistemas e signos diversos. Essa maleabilidade traz à tona questionamentos imprescindíveis para a compreensão do fenômeno: A relação com outros sistemas semióticos precisa ser repensada? Seriam eles meramente uma pré-história da escrita? Vê-los com outro olhar geraria uma certa instabilidade ao sistema herdado da escrita? O que realmente é recurso inédito na atualidade?

A importância de nos fazermos esses questionamentos reside no fato de que tendemos a considerar as TDICs, marca da nossa vida social na atualidade, com um ineditismo muito maior do que elas realmente possam oferecer, visto que, conforme Frade et. al. (2014), é apenas o digital que se cruza com a alfabetização. Entretanto, ressaltamos que alfabetização também se constrói nos seus aspectos materiais, pois muitas vezes há uma naturalização imperceptível da materialidade no ato abstrato de escrever, por exemplo. Conforme explica Chartier (2002) na história do livro e da leitura, muitas das decisões pedagógicas do século XIX para o século XX aconteceram em função da materialidade e não devido ao ato abstrato de escrever.

Todavia, não subestimemos a introdução TDICs, pois segundo Jenkins (2009), elas advêm de uma cultura que altera significativamente as relações sociais. Passamos a viver uma cultura da convergência de interesses, conteúdos, sistemas, linguagens, interfaces, fragmentações, camadas, multimodos de expressão e multigêneros, participação, efemeridade, atualização e consumo constantes, uma certa idealização do livre acesso e, inclusive, uma cultura marcada pelas exclusões. Tudo isso, sem dúvida, constitui o sujeito da sala de aula, cujas cenas, gestos, signos da cultura digital são incorporados pelos alunos. Essa cultura está inserida na mente e no corpo. É, por tanto, uma questão histórica e cultural que interfere no processo de ensino e de aprendizagem e não meramente uma questão de técnica, suporte e materialidades, ou seja, da tecnologia em si. 
Se em tempos e espaços anteriores, leitura e escrita nunca foram, no processo de alfabetização, habilidades discretas, na atual sociedade caracterizada por Santos (1998) como técnica, científica e informacional

O estudo do letramento [alfabetização ...] multimodal nas escolas e a sociedade começa com o importante reconhecimento de que a leitura e a escrita raramente são praticadas como habilidades discretas, mas estão intimamente ligadas ao uso de textos multimodais, muitas vezes em contextos digitais de uso. Além disso, há uma atenção crescente para os recursos multimodais e práticas de letramento que são praticadas em contextos sociais informais, como em residências e locais recreativos (MILLS; UNSWORTH 2018, p. 3, tradução nossa).

Essa atenção a recursos outros que não têm a escrita como centro, nos revela que estamos diante de uma alfabetização frente aos novos usos, suportes, gestos e valores, todavia, o foco continua no sujeito cultural e nas mediações para que consideremos a alfabetização na relação com a cultura digital. Nesse sentido, a alfabetização digital não se constitui como um conceito de fácil de construção, haja vista as múltiplas e aceleradas mudanças no acesso às mesmas e nas práticas sociais.

\begin{abstract}
À luz da teoria das multiliteracias, ler e escrever digitalmente configuram-se como processos singulares relativamente aos experienciados na era pré-digital: nos contextos digitais, as crianças constroem sentido de uma forma inegavelmente multimodal. Uma das implicações do reconhecimento dessa singularidade é a da necessidade de expandir o conceito de alfabetização, passando a prever a aprendizagem de um vasto conjunto de processos semióticos, que necessariamente inclui o modo escrito da linguagem verbal, embora indo muito além de uma consideração exclusiva. (PEREIRA, 2018, p. 25).
\end{abstract}

O ambiente digital possibilita, assim, outras formas de leituras, potencializando diferentes formas de linguagens, como a multimodal, e apontando outros caminhos que nos fazem escapar do pensamento restrito a uma alfabetização que se dá exclusivamente pela letra. Nos instiga a analisarmos e valorizarmos outros sistemas semióticos de alfabetização.

Ao pensarmos num tipo de alfabetização em que tornar-se letrado significa ter o domínio dos signos semióticos diversos que levarão o sujeito à leitura autônoma do mundo e dos seus fenômenos, logo nos remetemos à Cartografia, um saber geográfico que acompanha a história da humanidade e que existe antes do desenvolvimento da linguagem verbal, visto que esse saber refere-se às primeiras habilidades humanas para o atendimento da sua necessidade de representar graficamente a percepção espacial. Para Almeida (1999, p.132), a apropriação da linguagem cartográfica enquanto processo de aquisição de conhecimento assemelha-se à aquisição da leitura e escrita, uma vez que, ainda na infância, quando assimilamos "uma palavra em um texto, estamos aprendendo não só seu aspecto verbal, como também o sentido que sugere 
no contexto que a envolve. Sua aprendizagem ocorre de forma total, pois está vinculada ao sentido e não ao código". A esse respeito, Moreira (2007, p. 67-68) explica que

A leitura do mundo se faz por intermédio das categorias da localização e da distribuição, mesmo que o problema do primado da primeira sobre a segunda, as categorias da distribuição e da extensão entrando para o fim da montagem do discurso do geográfico como a unidade espacial dos fenômenos. Aí ainda aprendemos o ritual banal do trabalho geográfico: localizando-se e distribuindo-se é que se mapeia o mundo. E que todo trabalho geográfico consiste na seqüência clássica: primeiro localiza-se o fenômeno; depois monta-se a rede da sua distribuição; a seguir demarcase a extensão; por fim, transporta-se a leitura para a sua representação cartográfica. Mas tudo sendo verbalizado, ainda, na linguagem do mapa.

A necessidade de visualização e orientação espacial, ser capaz de fazer relações espaciais, reconhecer a distribuição espacial, associar e relacionar espacialmente os fenômenos, usar hierarquias espaciais, estabelecer conexões entre os lugares, os sistemas de orientação e referências, decorre de um tipo específico de alfabetização, a cartográfica, que possibilita ao sujeito compreender a construção do mundo e entender como a Geografia trabalha, ler e interpreta os fenômenos do espaço geográfico, visto que

A geografia lê o mundo por meio da paisagem. A cartografia é a linguagem que representa a paisagem. Este elo comum perdeu-se no tempo, e não por acaso ficaram ambas desatualizadas. Não houve atualização para uma e para outra. Até porque a iniciativa está com a geografia (MOREIRA, 2007, p. 67).

Atualmente recursos tecnológicos, como as imagens de satélite, permitem acesso fácil e rápido a quaisquer informações geográficas com o simples ato de um clique numa tela digital de computador, notebook, tablet ou smartphone. Isso representa, sem dúvida, um avanço fantástico para o conhecimento de diferentes partes do mundo e do lugar onde vivemos, pois conforme Chassot (2000, p.34) considerou: alfabetização é um "conjunto de conhecimentos que facilita aos homens e mulheres fazer uma leitura do mundo onde vivem", pelo que:

Reinventar a cartografia hoje é, portanto, criar uma cartografia geográfica. Afinal, o que está velho são os signos e significados guardados no mapa. A velha cartografia fala ainda a linguagem das medidas matemáticas, que longe estão de serem o enunciado de algum significado. As cores e os símbolos nada dizem. É uma cartografia cuja utilidade está preservada para alguns níveis, mas pouco serve para os níveis de significação. Permanece fundamental à leitura geográfica das localizações exatas, mas não para a leitura do espaço dinâmico das redistribuições de espaços fluidos. Serve para representar e descobrir significados dos espaços dos anos 1950. Contudo não tem serventia para ler os espaços de um novo milênio. É uma cartografia ainda necessária, todavia não mais suficiente. No entanto, os parâmetros de uma cartografia geográfica já estão postos: estão presentes na linguagem semiológica das novas paisagens. Mapear o mundo é antes de tudo adequar o mapa à essência ontológica do espaço. Representar sua tensão interna. Revelar os sentidos da coabitação do diverso. Falar espacialmente da sociedade a partir da sua tensão dialética. Mas tudo é impossível, repita-se, sem uma semiologia da imagem (MOREIRA, 2007, p. 68-69). 
No entanto, ao apropriar-nos das tecnologias digitais pensando apenas na inovação, somos vítimas de um paradoxo: o foco na inovação recai na constatação de uma metamorfose efêmera, que leva a uma desatualização das invenções nesse campo, cada vez mais, diverso. Não podemos nos perder na mistificação da inovação pela inovação. Sobre isso, a própria historicidade dos verbos ler e escrever nos ensina a enxergar que para além das rupturas, existem as continuidades. Compreender a inovação por esse viés nos permite a conceber a Cartografia efetivamente

Como uma semiologia de real significação -, compreender o espaço como modo de existência do homem, incluindo-o como um elemento essencial de sua ontologia, e permitir ao homem mais do que ver, pensar o espaço como seu modo de ser (MOREIRA, 2007, p. 70).

É preciso percebermos a existência de um diálogo entre as diferentes culturas como forma de aproveitarmos as potencialidades diversas, como dos avanços digitais por exemplo, sem com isso abandonarmos a nossa habilidade natural de explorar os espaços e territórios por meio das ferramentas da percepção - o olhar, o escutar, o tocar -, que foram nossos primeiros recursos tecnológicos. De acordo com Hall (1997, 1997 p. 16):

\begin{abstract}
Os seres humanos são seres interpretativos, instituidores de sentido. A ação social é significativa tanto para aqueles que a praticam quanto para os que a observam: não em si mesma, mas em razão dos muitos e variados sistemas de significado que os seres humanos utilizam para definir o que significam as coisas e para codificar, organizar e regular sua conduta na relação aos outros. Estes sistemas ou códigos de significado dão sentido às nossas ações. Eles nos permitem interpretar significativamente as ações alheias. Tomados em seu conjunto, eles constituem nossas 'culturas'. Contribuem para assegurar que toda ação social é 'cultural' que todas as práticas sociais expressam ou comunicam um significado e, neste sentido, são práticas de significação.
\end{abstract}

Por tanto, alfabetização e, no caso específico, alfabetização cartográfica deve ser compreendida como um processo em que junto à aprendizagem dos signos e sistemas de linguagem (como orientação, distribuição, relação e escala espaciais) há uma bagagem sociocultural dos sujeitos que nos remete a uma concepção de educação visual mais ampla.

Essa educação visual ampliada, no que concerne à alfabetização cartográfica, encontra na cultura digital uma importante aliada para a potencialização da mediação do saber cartográfico, sobretudo, quando nos debruçamos sobre os resultados divulgados, no ano de 2016, pelo Instituto Nacional de Estudos e Pesquisas Educacionais Anísio Teixeira (INEP), referentes a uma pesquisa etnográfica sobre letramento realizada num curso de licenciatura em Geografia. Esses resultados demonstraram que, o uso do quadro e giz ainda ocupa papel central no processo de formação geográfica em detrimento da utilização de recursos próprios do ensino da Geografia, a exemplo da leitura de mapas. 
Ora, a formação geográfica perpassa prioritariamente pelo domínio dos recursos que lhes são próprios, os quais, por suas especificidades, não se restringem ao uso do quadro e do giz como recursos materiais presentes no processo de ensino e de aprendizagem de qualquer saber. E nesse aspecto particular é que ganham importância pedagógica as TDICs, cujo domínio das técnicas demandam multiletramentos necessários à produção e leitura dos recursos multimodais próprios da ciência geográfica.

Nesse sentido, há uma necessidade um ensino cartográfico associado aos multiletramentos num contexto marcado pela predominância da cultura digital, que se caracteriza pela fluidez, diversidade e dinamismo, tendo em vista que:

[...] Em uma pedagogia dos multiletramentos, todas as formas de representação, incluindo a linguagem, devem ser considerados processos dinâmicos de transformação e não de reprodução [...]. A lógica dos multiletramentos é aquela que reconhece que a criação de significados é um processo ativo, transformador e uma pedagogia baseada nesse reconhecimento é mais provável que abra cursos de vida variáveis para um mundo de mudança e diversidade (COPE; KALANTZIS, 2009, p. 173 [tradução do autor]).

Esse dinamismo implica no processo de significação social das práticas de alfabetização cartográfica. Por isso, esse tipo de alfabetização, conforme Rojo (2013, p. 14), abrange dois princípios elementares: “[...] multiplicidade de linguagens, semioses e mídias envolvidas na significação para textos multimodais contemporâneos e por outro, para a pluralidade e a diversidade cultural trazidas pelos autores-leitores contemporâneos a essa criação de significação" (ROJO, 2013, p. 14).

No contexto das múltiplas linguagens, a geografia escolar tem na cartografia a sua linguagem específica que contribui para materializar o conhecimento geográfico escolar desde os anos iniciais de escolaridade. A linguagem cartográfica faz parte da multimodalidade de linguagens e é importante para o conhecimento geográfico na medida em que a linguagem cartográfica tem usos informais, mas ao aprender seus usos formais, esses facilitam a leitura e compreensão de um mapa temático. Isso significa reforçar a ideia de que o "mapa é uma construção social do mundo expressa pela Cartografia" (CASTELLAR, 2017, p. 14).

A apropriação dos recursos inerentes à cultura digital, desde que, conforme Pinto (2005), não seja reduzida ao aspecto da tecnologia como técnica, pode potencializar o ensino e a aprendizagem de conhecimentos diversos, a exemplo do saber cartográfico, que tem uma forma peculiar de linguagem, a cartográfica, compreendida como a ciência de um recurso híbrido e multimodal elementar da Geografia: o mapa temático. 


\section{CONSIDERAÇÕES FINAIS}

Concluímos, neste artigo, que alfabetização e letramento são processos indissociáveis quando se pretende uma formação cartográfica para além da mecanicidade, inclusive, num contexto marcado pelo domínio da cultura digital em que, conforme Pinto (2005), usualmente servimos à tecnologia, ou seja, ideologizamos esse termo e as potencialidades dos seus suportes de tal forma que nos perdemos num uso tecnocêntrico e acrítico, passando à condição de subservientes da técnica.

Apropriar-se da alfabetização como processo indissociável do letramento significa, segundo Street (2012, p. 78), “[...] realmente uma tentativa de lidar com os eventos e com os padrões de atividades de letramento, mas para ligá-las a alguma coisa mais ampla de natureza cultural e social", pelo que, os eventos de letramento permitem ao pesquisador captar, nos modos de ler, os movimentos que configurarão as práticas de leitura. Todavia, esse autor esclarece que a compreensão das práticas de letramento demanda também “[...] conversar com as pessoas, ouvi-las e ligar as experiências imediatas de leitura e escrita (dos leitores) a outras coisas que elas também façam" (STREET, 2012, p. 78).

Nesse sentido, artigos como este, que se caracterizou metodologicamente como uma revisão de literatura por meio de levantamentos, consultas e leituras de artigos, dissertações, teses, capítulos, livros e outras fontes que tratam da temática em estudo, apontam para a necessidade de estudos do tipo exploratório, de abordagem qualiquantitativa, que partam da combinação harmoniosa entre métodos quantitativos e qualitativos de produção e análise dos dados (FLICK, 2009), como forma de se investigar, do ponto de vista discursivo e empírico, as práticas de letramento cartográfico relacionadas à formação do bacharel e do professor de Geografia, sujeitos socialmente responsáveis pela leitura geográfica do mundo cartograficamente representado.

Essa investigação se faz necessária, sobretudo, quando nos debruçamos sobre os currículos dos cursos de Geografia no Brasil, nos quais há uma nítida divergência curricular no que concerne à formação cartográfica digital do bacharel e do licenciado em Geografia. Ou seja, enquanto no curso do tipo bacharelado em Geografia o núcleo cartográfico obrigatório é composto por disciplinas como Cartografia digital e Geoprocessamento, no curso do tipo licenciatura são excluídas essas disciplinas da formação curricular obrigatória do licenciando, limitando a sua formação a disciplinas introdutórias da Cartografia e Representação espacial, o 
que culmina num processo formativo que exclui a dimensão digital da formação cartográfica do professor de Geografia.

Todavia, a simples análise documental revela-se insuficiente quando se trata de investigar práticas de letramentos. Dessa forma, estudos que envolvem esse tipo de investigação aplicados ao campo da Cartografia, a observação participante enquanto processo em que, segundo Minayo (1993, p. 70), “o pesquisador se coloca como observador de uma situação social, com a finalidade de colher dados e compreender o contexto sob sua observação e, sem dúvida, modifica esse contexto, pois interfere nele, assim como é modificado pessoalmente", revela-se imprescindível para a possibilidade de um diálogo com categorias analíticas denominadas por krees e Van Leuween (2006) como metafunções: representacional, interativa e composicional.

Esse diálogo possibilita não só a apreensão dos conhecimentos, dos processos e das habilidades que fazem parte das práticas de letramento cartográfico, como permite analisar a relação dessas práticas e dos seus sujeitos com as TDICs a partir da percepção das vivências dos mesmos com os pressupostos teóricos da Gramática do Design Visual (GDV), teoria formulada por krees e Van Leuween (2006), que se constitui como uma das mais relevantes abordagens sobre textos não verbais.

No caso específico de estudos que tratam da alfabetização cartográfica na sua relação com o letramento e a cultura digital -, a GDV tem muito a contribuir para a compreensão do processo de letramento a partir dos recursos próprios da ciência geográfica, como no caso dos mapas temáticos, que se constituem, na concepção de Moreira (2007), como o repertório mais conspícuo de representação e leitura do mundo.

Esses estudos erigem como imprescindíveis diante das evidências de que o ensino da ciência geográfica, a exemplo da incipiente produção levantada com a realização do "estado do conhecimento" e dos resultados divulgados pelo INEP, continua centrado no quadro e no giz em detrimento do aproveitamento das inovações tecnológicas e das perspectivas dos novos estudos do letramento para o conhecimento cartográfico. Ou seja, a formação cartográfica parece estar em descompasso com uma cultura digital que atravessa o ensino, quer seja em relação aos novos suportes e materialidades dos conhecimentos, quer seja nos modos de vida, gestos e comportamentos dos sujeitos, os quais, tanto são consumidores como produtores de tecnologias. São sujeitos impregnados de cultura digital e que, ao mesmo tempo, ora são excluídos dessa cultura por barreiras econômicas, ora por reducionismos de práticas de ensino 
pautadas na existência de uma pré-história da escrita, na defesa do sistema fonográfico da escrita e na crença superficial de ineditismos, além de políticas curriculares construídas a partir de padrões clássicos enrijecidos do que venha a ser alfabetização cartográfica num contexto de ensino alterado pela cultura digital.

\section{REFERENCIAS}

ALMEIDA, R. D. de. Podemos estabelecer paralelos entre o ensino da leitura e escrita e o ensino de mapas? Boletim de Geografia, Maringá, n.1, ano 17, p.131-135, 1999.

ALMEIDA, R. D. de; PASSINI, E. Y. O espaço geográfico: ensino e representação. 7. ed. São Paulo: Contexto, 1999.

BAGNO, M. Linguagem. In: FRADE, I. C. A. S; VAL, M. da G. C. G; BREGUNCI, M. das G. C. Glossário Ceale de termos de Alfabetização, leitura e escrita par educadores. Belo Horizonte, CEALE/Faculdade de Educação da UFMG. 2014. Disponível em: http://www. ceale.fae.ufmg.br/app/webroot/glossarioceale/verbetes/linguagem. Acesso em: 18 abr. 2019.

BARTON, D. Literacy: an introduction to the ecology of written language. 2nd ed. Oxford: Blackwell, 2007.KRESS, Gunther. Literacy in the new media age. London: Routledge, 2007.

BERTIN, J. Teste de base da representação gráfica. Tradução Antônio Teixeira Neto. Revista Brasileira de Geografia, Rio de Janeiro, 42 (1): 160-182, jan-mar, 1980.

BICALHO, D. C. Leitura. In: FRADE, I. C. A. S; VAL, M. da G. C. G; BREGUNCI, M. das G. C. Glossário Ceale de termos de Alfabetização, leitura e escrita par educadores. Belo Horizonte, CEALE/Faculdade de Educação da UFMG. 2014. Disponível em: htttp://www. ceale.fae.ufmg.br/app/webroot/glossarioceale/verbetes/leitura. Acesso em: 18 abr. 2019.

BRASIL. Conselho Nacional de Educação. Parecer CNE/CES 492, de 03 de abril de 2001. Diretrizes Curriculares Nacionais dos cursos de Filosofia, História, Geografia, Serviço Social, Comunicação Social, Ciências Sociais, Letras, Biblioteconomia, Arquivologia e Museologia. Disponível em: http://portal.mec.gov.br/cne/arquivos/pdf/pcr492_01.pdf. Acesso em: 15 abr. 2019.

BRASIL. Resolução CNE/CP 2, de 01 de julho de 2015. Diretrizes Curriculares Nacionais para a formação inicial em nível superior (cursos de licenciatura, cursos de formação pedagógica para graduados e cursos de segunda licenciatura) e para a formação continuada. Disponível em: http://portal.mec.gov.br/docman/agosto-2017-pdf/70431-res-cnecp-002-03072015-pdf/file. Acesso em: 16 jan. 2019.

BRASIL. Parecer CNE/CP n ${ }^{\circ}$ 002/2015, de 25 jun. 2015. Diretrizes Curriculares Nacionais para a Formação Inicial e Continuada dos Profissionais do Magistério da Educação Básica. Disponível em: http://pronacampo.mec.gov.br/images/pdf/parecer_cne_cp_2_2015_ aprovado_9_junho_2015.pdf. Acesso em: 15 abr. 2019.

BRASIL. Constituição da República Federativa do Brasil, de 5 de outubro de 1988. Brasília, 1988. Disponível em: http://www.planalto.gov.br/ccvil_03/ constituiçao.htm-. Acesso em: 15 mai. 2019.

CAPDEVILA, J.; HARLEY, J. B. The new nature of maps: essays in the history of cartography. Biblio 3W, Revista Bibliográfica de Geografia y Ciencias Sociales, Universidad 
de Barcelona, Vol. VII, n. 404, 15 de octubre de 2002. Disponível em: http://www.ub.es/geocrit/b3w-404.htm. Acesso em: 23 abr. 2019.

CAPES - Coordenação de Aperfeiçoamento de Pessoal de Nível Superior. Banco de Teses. Disponível em: http://catalogodeteses.capes.gov.br/catalogo-teses/\#!/. Acesso em: 21 abr. 2019.

CARVALHO, F. F. Os significados composicionais e a formação de subjetividades na primeira página de jornais mineiros: um estudo de caso à luz da gramática do design visual. 2007. 124 p. Dissertação (Pós-graduação em Estudos Linguísticos). Faculdade de Letras, Universidade Federal de Minas Gerais, Belo Horizonte, 2007.

CASTELlAR, S. M. V.; VILHENA, J. A Linguagem e a Representação Cartográfica. In: CARVALHO, Anna Maria Pessoa de. Ensino de Geografia. São Paulo: Cengage Learning, 2010.

CASTELlAR, S. M. V. Cartografia Escolar e o Pensamento Espacial fortalecendo o conhecimento geográfico. Revista Brasileira de Educação em Geografia, v. 7, p. 1-245, 2017.

CHARTIER, R. A aventura do livro: do leitor ao navegador. Trad. Reginaldo de Moraes. São Paulo: Editora UNESP/ Imprensa Oficial do Estado, 1999. (1 $1^{\text {a }}$ reimpressão em 1998).

CHARTIER, R. À beira da falésia - A história entre certezas e inquietudes. Tradução de Patrícia Chittoni Ramos. Porto Alegre: Ed. Universidade, 2002.

CHASSOT, A. Alfabetização científica: Questões e desafios para a Educação. Ijuí: Editora UNIJUÍ, 2000.

COPE, B.; KALANTZIS, M. Multiliteracies: New literacies, new learning. Pedagogies: An International Journal, Nanyang Walk, v. 4, n. 3, 2009.

COSCARELLI, C. V. Textos versus hipertextos na teoria e na prática. In: COSCARELLI, C. V. (Org.) Hipertextos na teoria e na prática. Belo Horizonte: Autêntica, 2012.

CRAMPTON, J. W.; KRYGIER, J. An introduction to critical cartography. ACME: An international e-journal for critical geographies, v. 4, n.1, p.11-33, 2006.

DIONÍSIO, A. P.; VASCONCELOS, L. J. de. Multimodalidade, gênero textual e leitura. In: BUNZEN, C.; MENDONÇA, M. (Orgs.) Múltiplas linguagens para o ensino médio. São Paulo: Parábola Editorial, 2013.

FISCHER, S. R. História da Leitura. Trad. Claudia Freire. São Paulo: Editora Unesp, 2006.

FLICK, U. Introdução à pesquisa Qualitativa. Trad. Joice Elias Costa. 3.Ed. Porto Alegre: ARTMED, 2009.

FRADE, I. C. A. S. Alfabetização digital. In: VAL, M. da G. C. G; BREGUNCI, M. das G. C. Glossário Ceale de termos de Alfabetização, leitura e escrita par educadores. Belo Horizonte, CEALE/Faculdade de Educação da UFMG. 2014. Disponível em: http://ceale.fae.ufmg.br/app/webroot/glossarioceale/referencia/frade-i-c-a-s-alfabetizacaoaprendizagem-inicial-do-sistema-de-escrita-in-coscarelli-c-e-ribeiro-e-orgs-letramentodigitalaspectos-sociais-e-possibilidades-pedagogicas-belo-horizonte-autentica-2005. Acesso em: 18 abr. 2019.

FREIRE, P. Pedagogia da autonomia: saberes necessários à prática educativa. $36^{\circ}$ edição. São Paulo: Editora Paz e Terra, 1996. 
HALL, S. A centralidade da cultura: notas sobre as revoluções culturais do nosso tempo. Educação \& Realidade, Porto Alegre, v.22, n.2, p.15-46, jul/dez. 1997.

KENSKI, V. M. Educação e tecnologias: o novo ritmo da informação. (Coleção Papirus Educação). 8. ed. Campinas, SP: Papirus, 2012.

KRESS, G; BEZEMER J. Escribir en un mundo de representación multimodal. In: KALMAN e STREET (Coord.) Lectura, escritura e matemáticas - Diálogos com a América Latina. Mérico: single XXI, 2009.

KRESS, G. Literacy in the new media age. London: Routledge, 2003.

KRESS, G; VAN LEEUWEN, T. Reading Imagens: The Gramar of Visual Desing. 2. ed. London: Taylor e Francis e-Library, 2006.

JEWITT, C.; KRESS, G. R. Multimodal Literacie. New York: Peter Lang, 2003.

LOCH, R. E. N. Cartografia: representação, comunicação e visualização de dados espaciais. Florianópolis: Ed. Da UFSC, 2006.

MACEDO, M. S. A. N.; NEVES-JUNIOR, B. Letramento acadêmico em um curso de Geografia: uma perspectiva etnográfica. INEP. Revista Brasileira Estudos Pedagógicos. 2016, vol.97, n.245, pp.68-81.

MANEVY, A. Política da Cultura Digital. In: SAVAZONI, R.; CONH, S. (Org.). Cultura digital.br. Rio de Janeiro: Beco do Azougue, 2009.

MILLS, K. A.; UNSWORTH, L. Multimodal Literacy. Austrália, 2018. Disponível em: https://www.researchgate.net/publication/322950599_Multimodal_literacy. Acesso em: 05 jan. 2019.

MINAYO, M. C. de S. (Org.); DESLANDES, S. F.; GOMES, R. Pesquisa social: teoria, método e criatividade. 33 ed. Petrópolis, RJ: Vozes, 2013.

MOREIRA, R. Da região à rede e ao lugar: a nova realidade e o novo olhar geográfico sobre o mundo. Revista Eletrônica de Ciências Humanas e Sociais: Etc.. espaço, tempo e crítica. $\mathrm{N}^{\circ}$ 1(3), VOL. $1,1^{\circ}$ de junho de 2007. Disponível em: http://www2.fct.unesp.br/docentes/geo/raul/ cartografia_ensinoGeografia2016/racioc\%EDnio\%20geogr\%E1 fico\%20\%20ruy\%20moreira. pdf. Acesso em: 12 dez. 2019.

NÖTH, W. Panorama da semiótica: De Platão a Peirce. São Paulo: Annablume, 1995. Disponível em: https:// edisciplinas.usp.br/pluginfile.php/276607/mod_ resource/ content/1/panorama-da-semiotica-de-platao-a-peirce-pg-01-a-77-noth-winfried.pdf. Acesso em: 15 abr. 2019.

OLIVEIRA, I. J; NASCIMENTO, D. T. F. As geotecnologias e o ensino de cartografia nas escolas: potencialidades e restrições. In: Revista Brasileira de Educação em Geografia, v. 7, p. 158-172, 2017. Disponível em:

http://www.revistaedugeo.com.br/ ojs/index.php/revistaedugeo/article/view/491/233. Acesso em: 17 de abril de 2019.

PEREIRA, Í. S. P. Para uma redefinição da alfabetização na era da comunicação digital. Revista Brasileira de Alfabetização. Vol. 1, n. 8 (jul./dez. 2018). Belo Horizonte, MG: Associação Brasileira de Alfabetização - ABAlf. -. 240 p. Disponível em: 
http://abalf.org.br/wp-content/uploads/2019/12/Revista-ABAlf-Vol-1-n-8-20-COMPLETODigital.pdf. Acesso em 20 nov. 2019.

PINTO, Á. V. O conceito de Tecnologia. Rio de Janeiro: Contraponto, 2005.

ROMANOWSKI, J. P.; ENS, R. T. As pesquisas denominadas do tipo "estado da arte" em educação. Diálogo Educ., Curitiba, v. 6, n.19, set./dez. 2006.

ROJO, R. H. R. Gêneros discursivos do Círculo de Bakthin e multiletramentos. In: Multiletramentos na escola. (Org.). Escola conectada: os multiletramentos e as TICs. São Paulo: Parábola, 2013.

SANTAELLA, L. Navegar no ciberespaço: o perfil cognitivo do leitor imersivo.

São Paulo: Paulus, 2004.

SIMIELLI, M. E. R. Cartografia no ensino fundamental e médio. In: CARLOS, Ana Fani Alessandri (org.) A Geografia na sala de aula. São Paulo: Contexto, 2002.

SOARES, M. Letramento: um tema em três gêneros. $2^{\circ}$ ed. Belo Horizonte: Autêntica, 1999.

SOARES, M. Alfabetização. In: FRADE, I. C. A. S; VAL, M. da G. C. G; BREGUNCI, M. das G. C. Glossário Ceale de termos de Alfabetização, leitura e escrita par educadores. Belo Horizonte, CEALE/Faculdade de Educação da UFMG. 2014. Disponível em: http://www.ceale.fae.ufmg.br/app/webroot/glossarioceale/verbetes/alfabetização. Acesso em: 18 abr. 2019.

SOARES, M. Alfabetização: em busca de um método? Belo Horizonte. Educação em Revista, N. 12, dez/1990.

SOARES, M. Alfabetização e Letramento. São Paulo: Contexto, 2010.

STREET, B. Eventos de letramento e práticas de letramento: teoria e prática nos Novos Estudos do Letramento. In: MAGALHÂES, I. (Org.) Discursos e práticas de letramento: Pesquisa etnográfica e formação de professores. Campinas: Mercado de Letras, 2012.

UNESCO. A ciência para o século XXI: uma nova visão e uma base de ação. Brasília: UNESCO; ABIPTI, 2003. 